\title{
Article \\ Effect of Substrates on Femtosecond Laser Pulse-Induced Reductive Sintering of Cobalt Oxide Nanoparticles
}

\author{
Mizue Mizoshiri ${ }^{1, *(1)}$, Kyohei Yoshidomi ${ }^{1}$, Namsrai Darkhanbaatar ${ }^{1}$, Evgenia M. Khairullina ${ }^{2}$ \\ and Ilya I. Tumkin ${ }^{2}(\mathbb{C}$ \\ 1 Department of Mechanical Engineering, Nagaoka University of Technology, 1603-1, Kamitomioka, \\ Nagaoka 940-2142, Japan; s193097@stn.nagaokaut.ac.jp (K.Y.); s203050@stn.nagaokaut.ac.jp (N.D.) \\ 2 Institute of Chemistry, Saint Petersburg State University, 7/9 Universitetskaya Nab., \\ 199034 St. Petersburg, Russia; e.khayrullina@spbu.ru (E.M.K.); i.i.tumkin@spbu.ru (I.I.T.) \\ * Correspondence: mizoshiri@mech.nagaokaut.ac.jp
}

check for updates

Citation: Mizoshiri, M.; Yoshidomi, K.; Darkhanbaatar, N.; Khairullina,

E.M.; Tumkin, I.I. Effect of Substrates on Femtosecond Laser Pulse-Induced Reductive Sintering of Cobalt Oxide Nanoparticles. Nanomaterials 2021, 11 , 3356. https://doi.org/10.3390/ nano11123356

\section{Academic Editors:}

Christophe Donnet and Ion N. Mihailescu

Received: 19 October 2021 Accepted: 9 December 2021 Published: 10 December 2021

Publisher's Note: MDPI stays neutral with regard to jurisdictional claims in published maps and institutional affiliations.

Copyright: (c) 2021 by the authors. Licensee MDPI, Basel, Switzerland. This article is an open access article distributed under the terms and conditions of the Creative Commons Attribution (CC BY) license (https:/ / creativecommons.org/licenses/by/ $4.0 /)$.

\begin{abstract}
Direct writing of cobalt/cobalt oxide composites has attracted attention for its potential use in catalysts and detectors in microsensors. In this study, cobalt-based composite patterns were selectively formed on glass, polyethylene naphthalate (PEN), and polyethylene terephthalate (PET) substrates via the femtosecond laser reductive sintering of $\mathrm{Co}_{3} \mathrm{O}_{4}$ nanoparticles in an ambient atmosphere. $\mathrm{A} \mathrm{Co}_{3} \mathrm{O}_{4}$ nanoparticle ink, including the nanoparticles, ethylene glycol as a reductant, and polyvinylpyrrolidone as a dispersant, was spin-coated onto the substrates. Near-infrared femtosecond laser pulses were then focused and scanned across the ink films to form the patterns. The non-sintered nanoparticles were subsequently removed from the substrate. The resulting sintered patterns were found to be made up of $\mathrm{Co} / \mathrm{CoO}$ composites on the glass substrates, utilizing various pulse energies and scanning speeds, and the $\mathrm{Co} / \mathrm{CoO} / \mathrm{Co}_{3} \mathrm{O}_{4}$ composites were fabricated on both the PEN and PET substrates. These results suggest that the polymer substrates with low thermal resistance react with the ink during the reductive sintering process and oxidize the patterns more easily compared with the patterns on the glass substrates. Such a direct writing technique of cobalt/cobalt oxide composites is useful for the spatially selective printing of catalysts and detectors in functional microsensors.
\end{abstract}

Keywords: femtosecond laser reductive sintering; printing; $\mathrm{Co}_{3} \mathrm{O}_{4}$ nanoparticle ink; cobalt/cobalt oxide composite; polymer substrate

\section{Introduction}

There is considerable interest in the use of laser direct writing technologies in the fabrication of metal patterns for printed electronics because the techniques permit photolithographyfree electrode fabrication. Recently, low-cost non-noble metal electrodes, such as $\mathrm{Cu}$ and $\mathrm{Ni}$, have attracted attention as potential alternatives to $\mathrm{Ag}$ or Au electrodes. For example, it was shown that $\mathrm{Cu}$ and $\mathrm{Ni}$ microelectrodes can be sufficiently applied to the electrochemical detection of glucose [1]. Although many techniques, including inkjet, flexo, gravure, and screen printing, have been developed for the printed electronics process, the advantage of laser direct writing is that the patterning and the metallization can be performed simultaneously via the sintering or reductive sintering of nanoparticle inks. Cu nanoparticle inks have previously been coated and selectively sintered via irradiating continuous-wave and pulsed lasers on substrates [2-4]. Cu electroconductive patterns were formed on substrates after removing the non-sintered nanoparticles. An optimal laser scanning condition existed to obtain high electrical conductivity, which prevents the patterns from re-oxidizing or losses of energy [2]. However, the absorption of the laser light by the metal nanoparticle inks is generally low because of the high reflectance and scattering of the nanoparticles.

To increase the laser light absorption of the nanoparticles, metal oxide nanoparticles with small bandgaps have been used as the ink that makes up the metal oxide nanoparticles 
and reductant agents to increase the absorbance of the laser light [5-8]. In this method, the absorbed laser light induces reductive sintering of the metal oxide nanoparticles. In addition, the methods are generally vacuum-free processes of metallization. Cu patterns were formed via the reduction and sintering of copper oxide (I or II) nanoparticles mixed with a reductant. A CuO nanoparticle ink composed of $\mathrm{CuO}$ nanoparticles $(<50 \mathrm{~nm}$ in diameter), ethylene glycol, and polyvinylpyrrolidone (PVP) was coated on glass and flexible polyimide (PI) substrates [5]. Then, near-infrared or green continuous-wave and nanosecond pulsed lasers were focused onto the $\mathrm{CuO}$ nanoparticle ink films to reduce and sinter the ink. Finally, the non-sintered nanoparticles were removed by rinsing the samples in deionized water. $\mathrm{A} \mathrm{Cu}_{2} \mathrm{O}$ nanoparticle ink, including $\mathrm{Cu}_{2} \mathrm{O}$ nanoparticles, 2-propanol, and PVP, was also used for laser reductive sintering [6]. Formic acid was generated via the thermochemical reaction of 2-propanol and PVP.

$\mathrm{Ni}$ electrodes have also been fabricated via the laser reductive sintering of $\mathrm{NiO}$ nanoparticles $[7,8]$. The $\mathrm{NiO}$ nanoparticles mixed with toluene were reduced to $\mathrm{Ni}$ using protons supplied from the toluene molecules. To achieve this, the ink-deposited films were irradiated by green continuous-wave laser light in order to induce a thermochemical reduction in ambient conditions.

Femtosecond laser reductive sintering via single- and multi-photon absorption processes have also been developed to form Cu-based patterns [9-13]. In this process, thermal energy converted from the absorbed photon energy reduces the metal oxide nanoparticles. The femtosecond laser reductive sintering achieves non-equilibrium $\mathrm{Cu}$-rich and $\mathrm{Cu}_{2} \mathrm{O}$ rich patterns from copper oxide (I and II) nanoparticles by controlling the nature of the laser irradiation, including the laser scanning speed and pulse energy [9,10]. Additionally, high-purity $\mathrm{Cu}$ patterns without significant oxidation can be formed under inert gas injection [11]. $\mathrm{CuO} / \mathrm{NiO}$ mixed nanoparticle inks have been selectively sintered to form p-type $\mathrm{Cu}_{2} \mathrm{O} / \mathrm{NiO}$-rich and n-type $\mathrm{Cu}$-Ni-rich thermoelectric couples via careful control of the laser irradiation. It was found that p-type and n-type thermoelectric couples could be fabricated at low and high scanning speeds, respectively [12,13].

The ease with which metal oxide nanoparticles can be reductively sintered into a metal is determined by the standard free energy of formation of the metal oxide. Noble metal oxides, such as Ag and Au oxides, are easily reduced and sintered in air because the standard free energies of formation of the metal oxides are small $(<200 \mathrm{~kJ} / \mathrm{mol})$. In contrast, $\mathrm{Cu}$ and $\mathrm{Ni}$ usually require an inert atmosphere for sintering. Therefore, when $\mathrm{CuO}$ and $\mathrm{NiO}$ are reduced to $\mathrm{Cu}$ and $\mathrm{Ni}$, respectively, the use of reductant agents is necessary. However, other metal oxide nanoparticles have not been reported to be reduced to metals for patterning in air using the laser reductive sintering because the metal oxides are more stable than the metals.

Cobalt/cobalt oxide composites such as $\mathrm{Co}, \mathrm{CoO}$, and $\mathrm{Co}_{3} \mathrm{O}_{4}$, are promising materials for use in various applications and devices, including gas sensors, non-enzyme detectors, and energy storage [14-16]. We have already focused on the application of Co-based materials for the catalyst. Composites of bimetallic $\mathrm{Cu}$-Co systems or other systems where the catalytic effect is enhanced by the presence of two metals have also been shown to be promising candidates for electrochemical microsensors $[17,18]$. If the direct writing of composites such as cobalt and cobalt oxides were achieved, the rapid printing device would likely play an important role in the Internet of Things. These kinds of the metal, metal oxides, and their composites are generally fabricated using well-established semiconductor technology and the conventional powder sintering process [15]. However, these processes need the vacuum atmosphere to control the oxidation. In the femtosecond laser direct writing process, those materials are expected to be easily generated in air because the femtosecond laser pulses easily generate non-equilibrium materials, such as various valences of metal oxides, because rapid heating and cooling are achieved in the reductive sintering process [19]. Therefore, femtosecond laser reductive sintering of $\mathrm{Co}_{3} \mathrm{O}_{4}$ has a high potential for selectively patterning $\mathrm{Co}$ and cobalt oxides by controlling the laser irradiation conditions. 
In this study, we investigate the patterning properties of cobalt-based direct writing via the femtosecond laser reductive sintering of cobalt oxide nanoparticles. First, cobalt oxide nanoparticle inks are prepared and coated as films on various substrates, including glass and flexible polymer substrates, such as polyethylene naphthalate (PEN) and polyethylene terephthalate (PET), which are promising candidates for use as flexible devices [20]. Then, near-infrared femtosecond laser pulses are irradiated onto the metal oxide to generate metals. Cobalt-based patterns were fabricated via the femtosecond laser reductive sintering of $\mathrm{Co}_{3} \mathrm{O}_{4}$ nanoparticles.

\section{Materials and Methods}

\subsection{Preparataion of the $\mathrm{Co}_{3} \mathrm{O}_{4}$ Nanoparticle Ink}

$\mathrm{A} \mathrm{Co}_{3} \mathrm{O}_{4}$ nanoparticle ink was prepared using commercially available $\mathrm{Co}_{3} \mathrm{O}_{4}$ nanoparticles (Sigma Aldrich, St. Louis, MO, USA, particles with a diameter <50 nm), ethylene glycol, and PVP (Mw 10,000). The concentrations of the $\mathrm{Co}_{3} \mathrm{O}_{4}$ nanoparticles, ethylene glycol, and PVP were 33, 55, and 12 wt.\%, respectively. The PVP was first mixed with ethylene glycol, and the $\mathrm{Co}_{3} \mathrm{O}_{4}$ nanoparticles were then mixed with PVP-ethylene glycol solution using ultrasonic waves.

\subsection{Femtosecond Laser Direct Writing Process}

The femtosecond laser direct writing process was made up of three steps: (i) the coating of the ink on the substrates, (ii) the femtosecond laser direct writing, and (iii) the removal of the non-sintered nanoparticles, and this process is shown schematically in Figure 1. In the coating step, the $\mathrm{Co}_{3} \mathrm{O}_{4}$ nanoparticle ink was spin-coated on various substrates, including glass, PEN, and PET. The thickness of the coated ink film was $\sim 10 \mu \mathrm{m}$ at the spinning rate of $7000 \mathrm{rpm}$, which allowed to form the patterns with adhesion on the substrates. The parameters of the glass, PEN, and PET substrates are shown in Table 1. By considering the thermal properties, such as thermal conductivity, heat capacity, and density of the substrates, the thickness of the PEN and PET substrates was determined to be approximately four times thinner than that of the glass substrates.

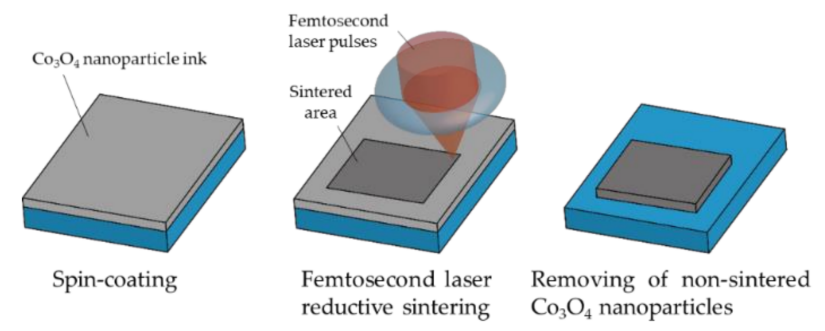

Figure 1. Procedure for the laser direct writing of cobalt/cobalt oxide composite materials using femtosecond laser reductive sintering of cobalt oxide nanoparticles.

Table 1. Physical parameters of the substrates.

\begin{tabular}{|c|c|c|c|c|c|c|c|}
\hline & $\begin{array}{l}\text { Thickness } \\
\text { (mm) }\end{array}$ & $\begin{array}{c}\text { Thermal } \\
\text { Conductivity } \\
\text { (W/K·m) }\end{array}$ & $\begin{array}{c}\text { Heat } \\
\text { Capacity } \\
(\mathrm{J} / \mathrm{K} \cdot \mathrm{kg})\end{array}$ & $\begin{array}{l}\text { Density } \\
\left(\mathrm{kg} / \mathrm{m}^{3}\right)\end{array}$ & $\begin{array}{c}\text { Glass } \\
\text { Transition } \\
\text { Temperature } \\
\left({ }^{\circ} \mathrm{C}\right)\end{array}$ & $\begin{array}{c}\text { Melting } \\
\text { Point }\left({ }^{\circ} \mathrm{C}\right)\end{array}$ & Ref. \\
\hline Glass & 1 & 1.38 & 703 & 2203 & $\sim 1700$ & $>1700$ & [21] \\
\hline $\begin{array}{c}\text { PEN } \\
\text { (Teonex, Teijin) }\end{array}$ & $\sim 0.25$ & $\sim 0.2$ & 0.87 & $\sim 1330$ & 121 & 269 & [22] \\
\hline $\begin{array}{c}\text { PET } \\
\text { (Lumirror, Toray) }\end{array}$ & $\sim 0.25$ & $\sim 0.14$ & 0.32 & $\sim 1400$ & 155 & 263 & [23] \\
\hline
\end{tabular}


Femtosecond laser pulses with Gaussian distributions $\left(\mathrm{M}^{2}=1.1\right)$ were then focused and scanned on the surface of the ink using an objective lens with a numerical aperture of 0.45 . The focal spot on the ink surface was approximately $3 \mu \mathrm{m}$, measured using a knife edge method. The wavelength, pulse duration, and repetition frequency of the femtosecond laser pulses used were $780 \mathrm{~nm}, 120 \mathrm{fs}$, and $80 \mathrm{MHz}$, respectively. The laser pulse energy was varied across energies less than $0.74 \mathrm{~nJ}$. The sample substrates were scanned to form arbitrary shape patterns using an XYZ-mechanical stage (ALIO INDUSTRIES, INC., Arvada, $\mathrm{CO}$, USA). An air-flow system was used during the laser irradiation to avoid covering the surface of the objective lens with the vapors generated by the thermochemical reduction of the $\mathrm{Co}_{3} \mathrm{O}_{4}$. Considering the bandgap of $\mathrm{Co}_{3} \mathrm{O}_{4}(\sim 1.5 \mathrm{eV})[24,25]$, the laser pulses with the near-infrared light are expected be absorbed by the cobalt oxide nanoparticle ink. Finally, following the irradiation procedure, any non-sintered nanoparticles on the substrates were removed by rinsing the substrate in ethylene glycol and ethanol. The ethylene glycol and $\mathrm{PVP}$ in the $\mathrm{Co}_{3} \mathrm{O}_{4} \mathrm{NP}$ ink were expected to reduce $\mathrm{Co}_{3} \mathrm{O}_{4}$ to $\mathrm{Co}$ and $\mathrm{CoO}$ according to the following equations $[5,15,26]$ :

$$
\begin{gathered}
2 \mathrm{HO}\left(\mathrm{CH}_{2}\right)_{2} \mathrm{OH}->2 \mathrm{C}_{2} \mathrm{H}_{4} \mathrm{O}+\mathrm{H}_{2} \mathrm{O}(\mathrm{g}) \\
2 \mathrm{C}_{2} \mathrm{H}_{4} \mathrm{O}+\mathrm{Co}_{3} \mathrm{O}_{4} \rightarrow 2 \mathrm{C}_{2} \mathrm{H}_{4} \mathrm{O}_{2}+2 \mathrm{H}+2 \mathrm{e}^{-}+\mathrm{Co}^{2+} / \mathrm{Co}^{3+}+\mathrm{O}^{2-} \\
\rightarrow \mathrm{Co} / \mathrm{CoO}+2 \mathrm{C}_{2} \mathrm{H}_{4} \mathrm{O}_{2}+\mathrm{H}_{2} \mathrm{O}(\mathrm{g}) .
\end{gathered}
$$

\subsection{Evaluation of the Patterns and Substrates}

The line width and the morphology of the resulting patterns were evaluated using an optical microscope (Keyence, Osaka, Japan, VHX-500F) and scanning electron microscopy (Hitachi, Tokyo, Japan, FlexSEM 1000 II). The crystal structures of the sintered patterns were examined using an X-ray powder diffractometer (Rigaku Corporation, Tokyo, Japan, MiniFlex) using $\mathrm{Cu}-\mathrm{K} \alpha$ radiation. The composition of the fabricated patterns was also analyzed using an energy dispersive X-ray spectrometer (Oxford Instruments, Abingdon, UK) attached to the SEM. Cross-sectional profiles of both the line patterns and raster scanned patterns were measured using a stylus profiler (Ulvac Inc., Chigasaki, Japan, Dektak $6 \mathrm{M})$. The damages of the substrates were examined using attenuated total reflection Fourier transform infrared spectroscopy (ATR-FTIR spectroscopy, Shimadzu Corp., Kyoto, Japan, Affinity-1).

\section{Results and Discussion}

\subsection{Absorption Properties of the $\mathrm{Co}_{3} \mathrm{O}_{4}$ Nanoparticle Ink}

Figure 2 shows the absorption properties of the $\mathrm{Co}_{3} \mathrm{O}_{4}$ nanoparticle ink film coated on a $\mathrm{SiO}_{2}$ glass substrate. The intense absorption at the wavelength of $780 \mathrm{~nm}$ indicates that the femtosecond laser pulses of the near-infrared light were absorbed via a single-photon absorption process.



Figure 2. Absorption spectrum of the $\mathrm{Co}_{3} \mathrm{O}_{4}$ nanoparticle ink film coated on the $\mathrm{SiO}_{2}$ glass substrate. 


\subsection{Line Width}

Line patterns were formed on various substrates with the aim of evaluating the effect of the substrates on the line width. Figure $3 a-c$ show optical microscope images and the cross-sectional profiles of the minimum line patterns fabricated on glass, PEN, and PET substrates. Continuous line patterns were formed on all the substrates. The minimum pulse energy on PEN substrates required for the continuous line patterning was higher than that on PET substrates. The heat capacity of PEN is higher than that of PET, even though the other parameters such as thermal conductivity, density, and melting point are also the same. As a result, higher pulse energy was thought to be required for the patterning on PEN than on PET. These results were consistent with the $\mathrm{Cu}$ precipitation using femtosecond laser pulses on glass and polydimethylsiloxane substrates [27]. The heights of the center of the lines was lower than both sides, suggesting that the high peak intensity of the laser pulses decreased the height because of the high dense sintering. The properties are thought to be caused by femtosecond laser pulses with the Gaussian profile, which are the same shapes reported previously [28]. The finer patterns were formed on glass substrates even though the pulse energy was higher than that on PEN and PET. These results indicate that the low thermal conductivity of PEN and PET achieved a higher temperature than that on glass substrates. All the line patterns were wider than the focal spot diameter, indicating that the thermal diffusion increased the line width.

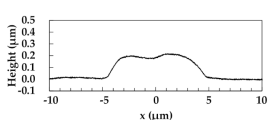

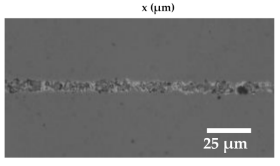

(a)

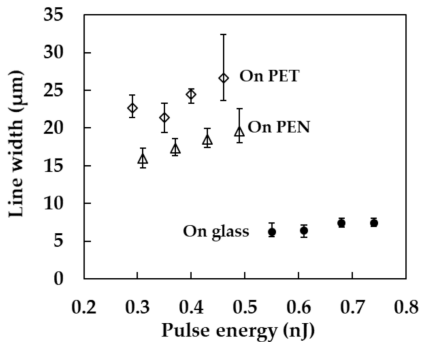

(d)
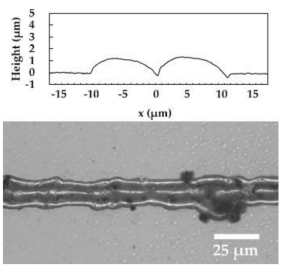

(b)
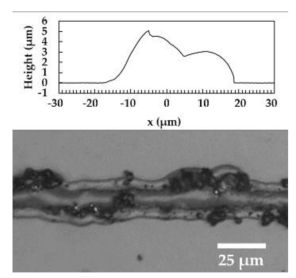

(c)

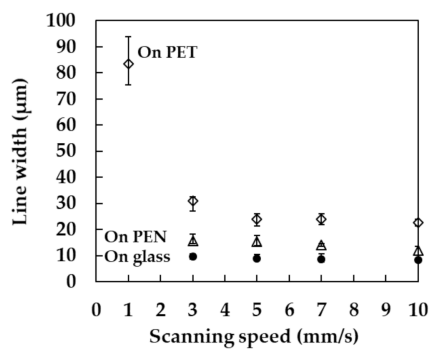

(e)

Figure 3. (a-c) Optical microscope images and cross-sectional profiles of the minimum line patterns fabricated on glass, PEN, and PET substrates, respectively. Dependences of the line width of the patterns on (d) the pulse energy at a scanning speed of $5 \mathrm{~mm} / \mathrm{s}$ and (e) the scanning speed. The data points shown correspond to energies of $0.29,0.31$, and $0.68 \mathrm{~nJ}$ on PET, PEN, and glass substrates, respectively.

\subsection{Crystal Structures of the Patterns on Various Substrates}

The crystal structures of the patterns fabricated on the glass substrates are shown in Figure 4 . The patterns of $5 \times 3 \mathrm{~mm}^{2}$ were fabricated by raster scanning of the focal spot. The raster pitch was determined to be $5 \mu \mathrm{m}$ by considering the line width shown in Figure 3. The dependence of the crystal structures on the pulse energy for a scanning speed of $5 \mathrm{~mm} / \mathrm{s}$ is shown in Figure 4a. The patterns fabricated with a pulse energy of more than $0.55 \mathrm{~nJ}$ adhered to the glass substrates after rinsing the samples, which was undertaken to remove the non-sintered nanoparticles. The X-ray diffraction (XRD) peaks corresponding to the fcc-Co increased with decreasing pulse energy. In contrast, the $\mathrm{XRD}$ peaks corresponding to $\mathrm{CoO}$ increased with increasing pulse energy. The peaks corresponding to $\mathrm{Co}_{3} \mathrm{O}_{4}$ disappeared after the laser irradiation. The dependence of the crystal structures on the scanning speed is shown in Figure $4 \mathrm{~b}$. The fcc-Co generation 
increased with increasing scanning speed, whereas the generation of $\mathrm{CoO}$ increased with decreasing scanning speed. These results suggest that increasing the irradiation energy increases the generation of $\mathrm{CoO}$. The $\mathrm{Co}_{3} \mathrm{O}_{4}$ nanoparticles were reduced via the following process [26]:

$$
\mathrm{Co}_{3} \mathrm{O}_{4}->\mathrm{Co}(\mathrm{fcc})(\text { reduced })+\mathrm{CoO} \text { (re-oxidized) (in air) }
$$

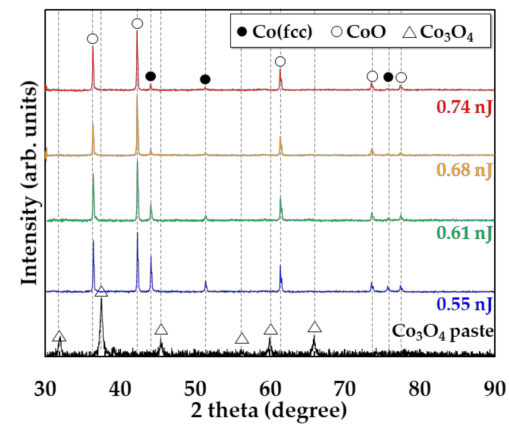

(a)

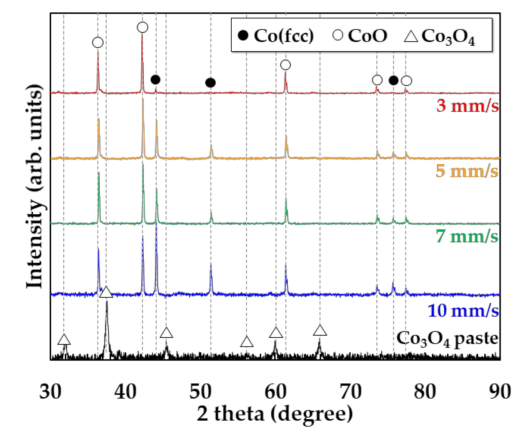

(b)

Figure 4. Crystal structures of the patterns fabricated on glass substrates (a) at a scanning speed of $5 \mathrm{~mm} / \mathrm{s}$ and a pulse energy of $0.55-0.74 \mathrm{~nJ}$, and $(\mathbf{b})$ a scanning speed in the range $3-10 \mathrm{~mm} / \mathrm{s}$ with a pulse energy of $0.55 \mathrm{~nJ}$.

To evaluate the effect of the substrate material on the crystal structures of the patterns, the crystal structures of the patterns on the PEN and PET substrates were investigated, as shown in Figure 5 . The patterns of $5 \times 3 \mathrm{~mm}^{2}$ were fabricated by raster scanning with the raster pitch of $5 \mu \mathrm{m}$. The patterns formed on the PET and PEN substrates remained on the substrate after rinsing even at low pulse energy, unlike those on the glass substrates. These results suggest that PEN and PET substrates with low thermal resistance and low thermal conductivity improved the adhesion of the patterns to the substrate by achieving high temperatures and reacting with the patterns. In addition, $\mathrm{Co}_{3} \mathrm{O}_{4}$ was observed in the patterns on the PEN and PET substrates, whereas it was not observed in the patterns on the glass substrates. To compare the oxides in the patterns on the glass, PEN, and PET substrates, the generation ratios of $\mathrm{Co}$ and $\mathrm{CoO}$ in the patterns are shown in Figure 6. The Co content in the patterns on the glass substrates increased by preventing the reoxidation by using a low pulse energy; in the case of the PET and PEN substrates, the intensity ratios of $\mathrm{Co} / \mathrm{CoO}$ exhibited peaks at a pulse energy of 0.43 and $0.31 \mathrm{~nJ}$, respectively. These results suggest that the PET and PEN substrates with low thermal resistance and containing oxygen reacted with the patterns and easily generated oxides, including $\mathrm{Co}_{3} \mathrm{O}_{4}$ and $\mathrm{CoO}$. Furthermore, the balance between the reduction and reoxidation caused the different composition ratios of $\mathrm{Co} / \mathrm{CoO}$ depending on the pulse energy, which has been reported previously in femtosecond laser reductive sintering of $\mathrm{CuO}$ nanoparticles [19]. The reason why the Co was generated at a lower pulse energy on PET than on PEN was thought to be that PET was heated easier than PEN because its heat capacity is smaller than that of PEN, even though the other parameters are almost the same, as shown in Table 1. In addition, the pulse energy for pattering on PEN and PET substrates was lower than that on glass substrates to prevent melting the polymer substrates. As a result, $\mathrm{CoO}$ in the patterns on PET and PEN substrates possibly came from the reduction of $\mathrm{Co}_{3} \mathrm{O}_{4}$ and reoxidation of $\mathrm{Co}$, and $\mathrm{Co}_{3} \mathrm{O}_{4}$ possibly came from raw materials and reoxidation of the reduced $\mathrm{Co}_{3} \mathrm{O}_{4}$. The cobalt/cobalt oxide composites were expected to be generated in an oxygen-rich atmosphere:

$$
\begin{gathered}
\left.\mathrm{Co}_{3} \mathrm{O}_{4}->\mathrm{Co}(\text { fcc })(\text { reduced })+\mathrm{CoO} \text { (reduced } / \text { re-oxidized }\right)+\mathrm{Co}_{3} \mathrm{O}_{4} \\
\text { (remained } / \text { re-oxidized) (in air) }
\end{gathered}
$$




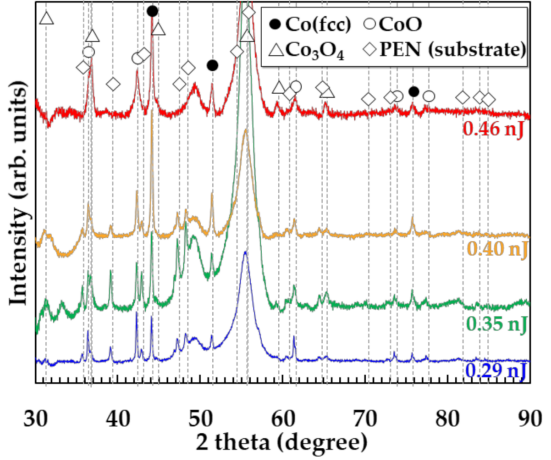

(a)

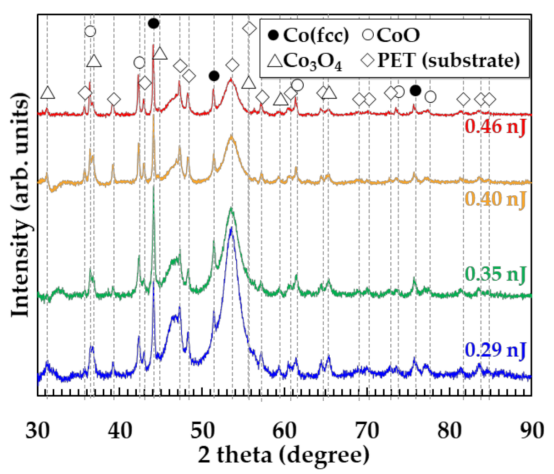

(c)

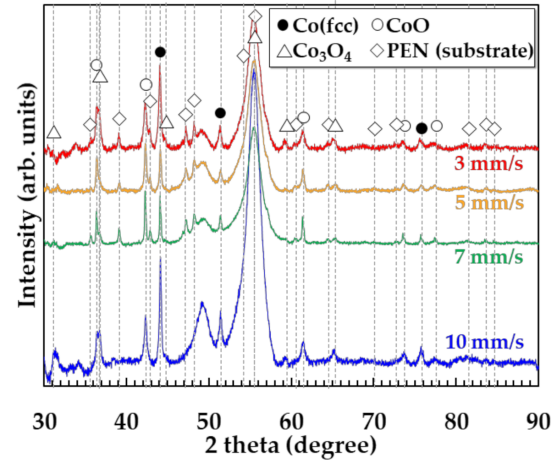

(b)

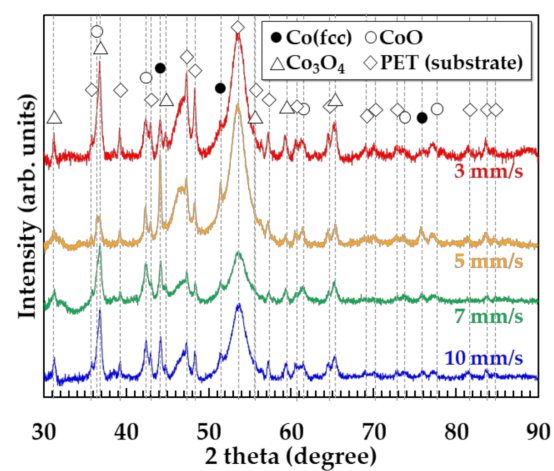

(d)

Figure 5. Crystal structures of the patterns fabricated on the PEN substrates (a) at a scanning speed of $5 \mathrm{~mm} / \mathrm{s}$ and pulse energy in the range $0.29-0.46 \mathrm{~nJ}$, and (b) with a scanning speed in the range $3-10 \mathrm{~mm} / \mathrm{s}$ and a pulse energy of $0.29 \mathrm{~nJ}$. Crystal structures of the patterns fabricated on PET substrates (c) at a scanning speed of $5 \mathrm{~mm} / \mathrm{s}$ and pulse energy in the range 0.29-0.46 $\mathrm{nJ}$, and (d) with a scanning speed in the range $3-10 \mathrm{~mm} / \mathrm{s}$ and a pulse energy of $0.29 \mathrm{~nJ}$.

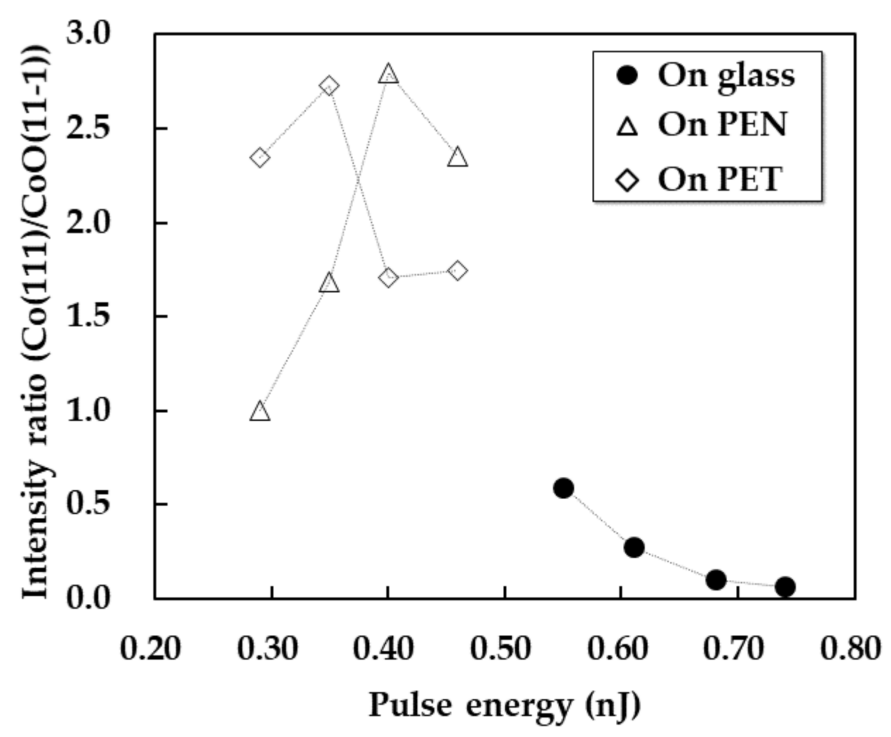

Figure 6. Intensity ratio of $\mathrm{Co}(111) / \mathrm{CoO}(111)$ of the patterns fabricated at a scanning speed of $5 \mathrm{~mm} / \mathrm{s}$ on the glass, PEN, and PET substrates.

\subsection{Damage of the Substrates}

Figure 7 shows SEM images and EDS mappings of the patterns $\left(5 \times 3 \mathrm{~mm}^{2}\right)$ fabricated on the glass, PEN, and PET substrates, which were the same samples shown in Section 3.3. The scanning speed was $5 \mathrm{~mm} / \mathrm{s}$. The pulse energy was 0.55 and $0.74 \mathrm{~nJ}$ on the glass substrates, and 0.29 and $0.46 \mathrm{~nJ}$ on PEN and PET substrates, which generated minimum 
and maximum line width at a scanning speed of $5 \mathrm{~mm} / \mathrm{s}$, respectively. Both cobalt and oxygen elements were observed in the same area of the glass substrates, although carbon was not observed in significant quantities (Figure 7a,b). These results indicate that the PVP in the ink was vapored during the reductive sintering process. Observing the crystal structure shown in Figure 4, we conclude that the $\mathrm{Co} / \mathrm{CoO}$ composite patterns were formed via the reductive sintering of $\mathrm{CO}_{3} \mathrm{O}_{4}$ nanoparticles. In contrast, the PEN and PET substrates were seen to be significantly damaged, which was different from the glass substrates. To confirm that the patterns were fabricated by sintering under specific conditions, FE-SEM images are shown in Figure $7 \mathrm{~g}$, h. The patterns were fabricated on the PEN substrate using a scanning condition of $5 \mathrm{~mm} / \mathrm{s}$ and a pulse energy of $0.29 \mathrm{~nJ}$, which was the same as the patterns shown in Figure 7c. Unlike the patterns on glass substrates, the $\mathrm{Co}_{3} \mathrm{O}_{4}$ nanoparticles were sintered, not melted, on PEN substrates. The patterns exhibited electrical conductivity. The resistance of the pattern $\left(5 \times 3 \mathrm{~mm}^{2}\right)$ was approximately $500 \Omega$ (length: $5 \mathrm{~mm}$ ) due to the presence of the oxide phase, as well as due to the high porosity. It should be noted that such values are quite suitable for the use of the synthesized structures as microelectrodes for electrochemical analysis of bioanalysis. The resistance measured a couple of months later was almost the same as that of as-prepared structures, indicating that the outermost surface of the precipitation was stable cobalt oxides. The adhesion of the patterns was also evaluated simply using the taping test. The patterns remained on PEN and PET substrates, although the patterns on glass substrates did not survive. In addition, the patterns on PEN and PET substrates survived after bending a few times.

To evaluate the damage of the PEN and PET substrates, the cross-sectional profiles of the patterns $\left(5 \times 3 \mathrm{~mm}^{2}\right)$ were measured as shown in Figure $8 \mathrm{a}-\mathrm{c}$. The cross-sectional profiles were vertical to the raster scanning direction. The cross-sectional profiles of the patterns on glass substrates were not dependent on the pulse energy, as shown in Figure 8a. However, the cross-sectional profiles of the patterns fabricated at a pulse energy of $0.46 \mathrm{~nJ}$ on PEN and all the patterns on PET substrates exhibited damages on the substrates because the heights of the patterns were lower than the surface levels of the substrates. These results suggest that the thermal volatilization was caused by irradiating excess pulse energy. The intense adhesion of the patterns on PEN and PET substrates also agreed with the results that the patterns and the substrates reacted chemically. In addition, the ATR-FTIR spectra of the patterns on PEN and PET substrates are shown in Figure 9a,b to evaluate the damages of the polymer substrates. The absorption peaks corresponding to the PEN decreased in the case of the pulse energy of $0.46 \mathrm{~nJ}$. The absorption peaks corresponding to the PET increased at the high pulse energy of $0.46 \mathrm{~nJ}$ compared to the low pulse energy of $0.29 \mathrm{~nJ}$. This result was consistent with the previous report that the absorption of PET improved by heating at high temperatures [29].

In comparison with the Co-composite patterns fabricated on the glass substrates, the patterns fabricated on the PET and PEN substrates were more easily oxidized, but metal Co remained in the patterns. Such spatially selective sintering process of a Co composite is an effective method to generate the Co-based catalysts in various gas and glucose sensors. In addition, the Co-based micropatterns will be used not only for direct application as microelectronics, but also as blanks for further modification, as shown earlier [30]. Here, femtosecond laser pulses were used for reductive sintering of $\mathrm{Co}_{3} \mathrm{O}_{4}$ nanoparticles because the total irradiated energy is expected to be reduced for the sintering using the high intensity of the laser pulses. The pulse duration of the femtosecond laser pulses is shorter than the duration of the thermal diffusion, resulting that the total irradiated energy can be reduced for the sintering of the nanoparticles. By considering the thermal diffusion, a picosecond pulsed laser is also a candidate for the reductive sintering. 

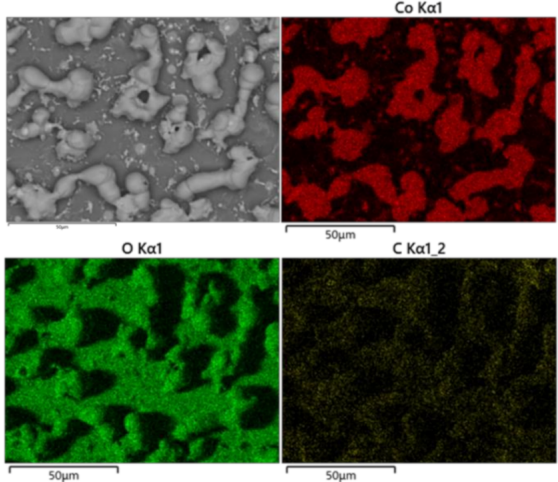

(a)
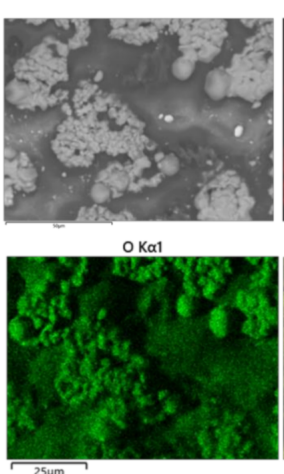

(c)

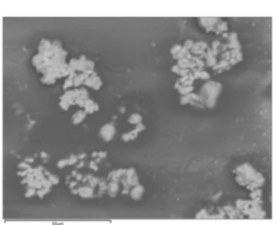

$\mathrm{OK} \alpha 1$

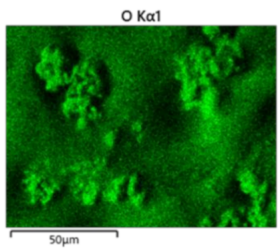

(e)

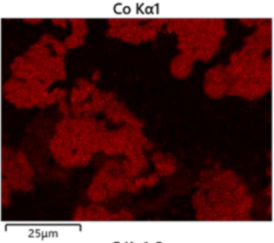

$\mathrm{CKal}_{2} 2$
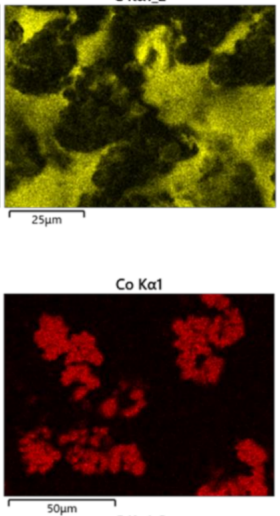

CKa1_2

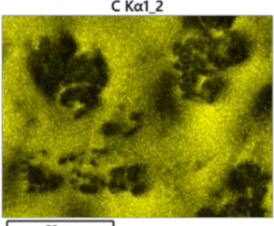

e)

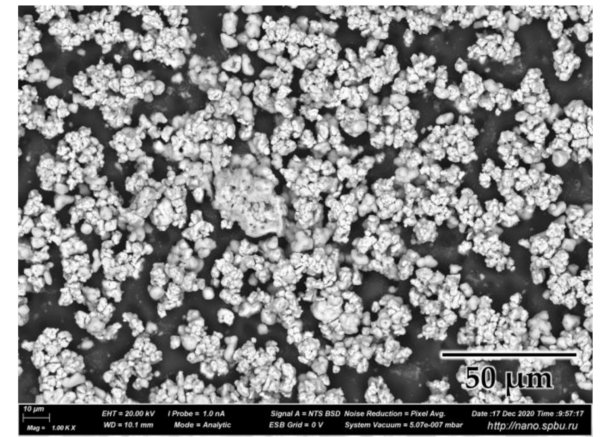

(g)
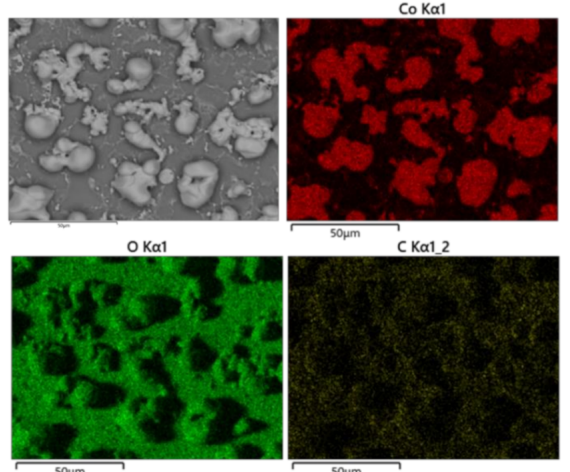

(b)
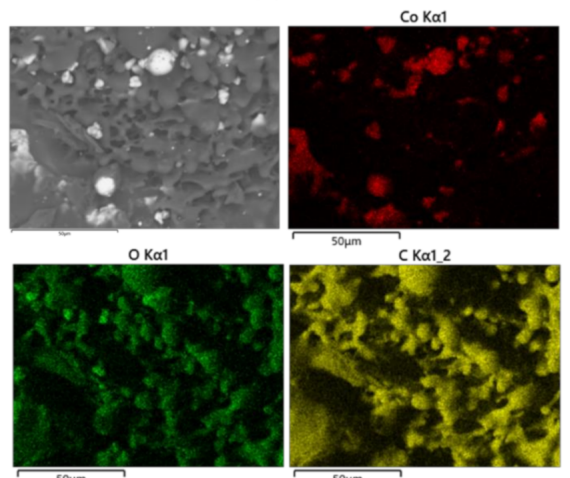

(d)
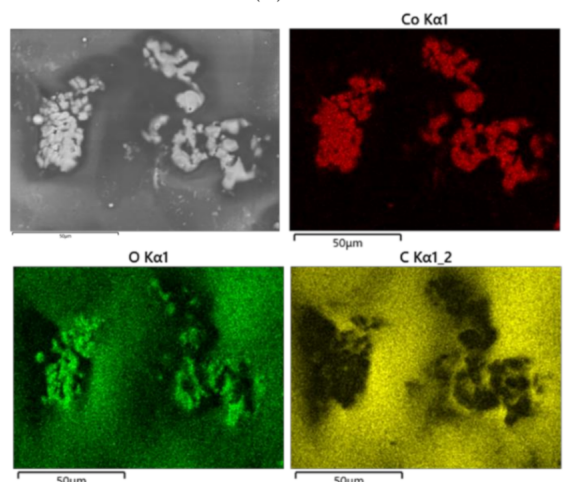

(f)

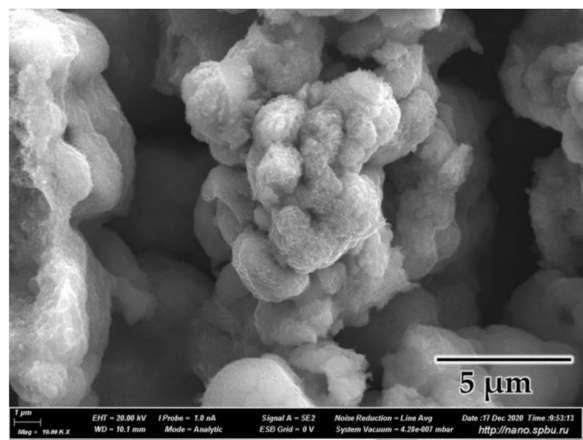

(h)

Figure 7. SEM images and EDS mappings of the patterns fabricated on glass, PEN, and PET substrates using a scanning speed of $5 \mathrm{~mm} / \mathrm{s}$, and a laser pulse energy of (a) $0.55 \mathrm{~nJ}$ and (b) $0.74 \mathrm{~nJ}$ on glass substrates, (c) $0.29 \mathrm{~nJ}$ and (d) $0.46 \mathrm{~nJ}$ on PEN substrates, and (e) $0.29 \mathrm{~nJ}$ and (f) $0.46 \mathrm{~nJ}$ on PET substrates. (g) FE-SEM image of the patterns fabricated on PEN substrates using a scanning speed of $5 \mathrm{~mm} / \mathrm{s}$ and a laser pulse energy of $0.29 \mathrm{~nJ}$, and (h) an enlarged image of (g). 


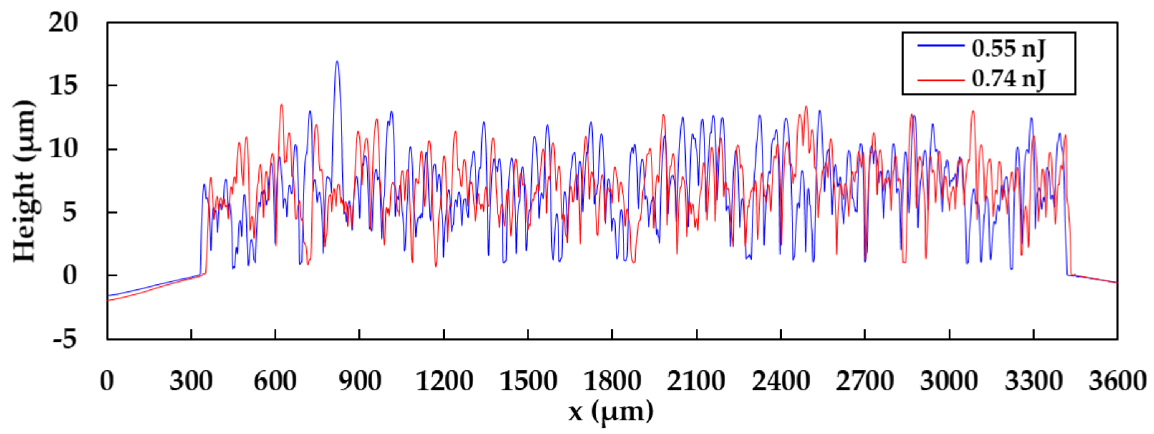

(a)

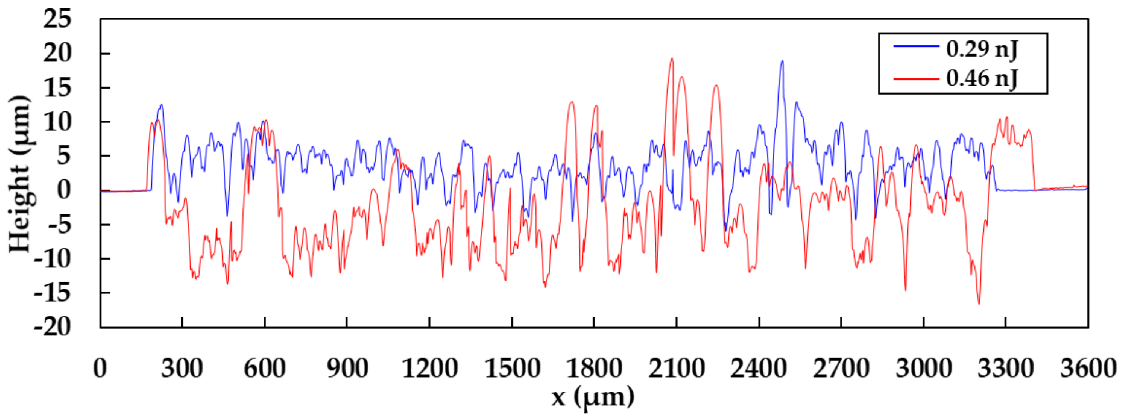

(b)

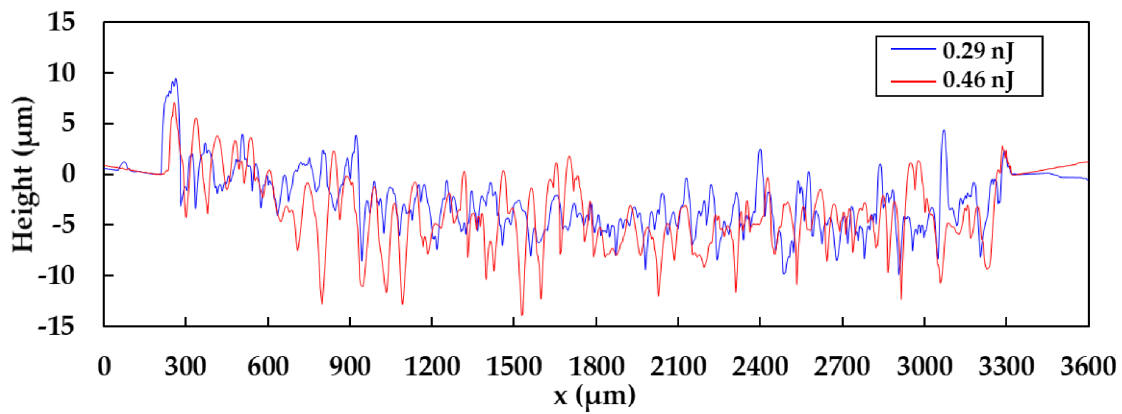

(c)

Figure 8. Cross-sectional profiles of the patterns fabricated at a pulse energy of (a) 0.55 and $0.74 \mathrm{~nJ}$ on glass substrates, and at a pulse energy of 0.29 and $0.46 \mathrm{~nJ}$ on (b) PEN and (c) PET substrates.

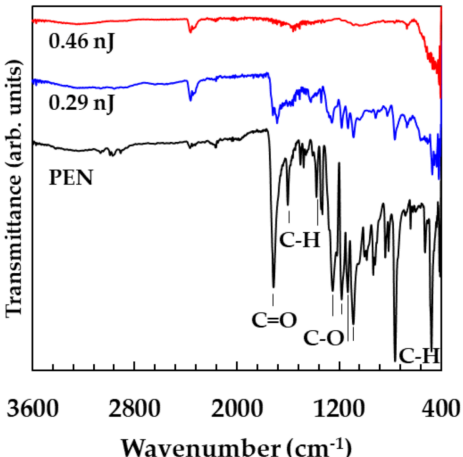

(a)

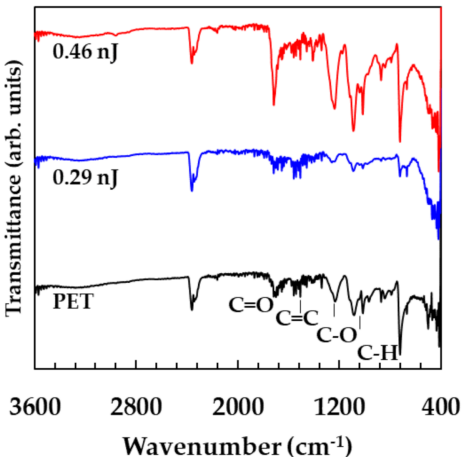

(b)

Figure 9. FT-IR spectra of the patterns on (a) PEN and (b) PET substrates.

\section{Conclusions}

Cobalt/cobalt oxide composite patterns were formed on glass, PEN, and PET substrates via the femtosecond laser reductive sintering of cobalt oxide nanoparticles in an ambient atmosphere. 
(1) $\mathrm{A} \mathrm{Co}_{3} \mathrm{O}_{4}$ nanoparticle ink, composed of the $\mathrm{Co}_{3} \mathrm{O}_{4}$ nanoparticles, ethylene glycol as a reductant, and PVP as a dispersant, was spin-coated on the substrates. The ink film exhibited sufficient absorption at the wavelength of the near-infrared femtosecond laser pulses.

(2) $\mathrm{Co} / \mathrm{CoO}$ composites were fabricated on glass substrates without significant generation of $\mathrm{Co}_{3} \mathrm{O}_{4}$. In contrast, $\mathrm{Co} / \mathrm{CoO} / \mathrm{Co}_{3} \mathrm{O}_{4}$ composites were formed on both the PEN and PET substrates. These results suggest that the polymer substrates with low thermal resistance reacted with the patterns and oxidized the patterns to a greater extent than occurred with the patterns on glass substrates.

Such direct writing technique of the cobalt/cobalt oxide composites is useful for spatially selective printing of the catalysts and detectors of the functional microsensors.

Author Contributions: Conceptualization, M.M. and I.I.T.; methodology, M.M., K.Y., N.D. and I.I.T.; validation, M.M., E.M.K. and I.I.T.; formal analysis, M.M., E.M.K. and I.I.T.; investigation, K.Y. and N.D.; resources, M.M.; data curation, M.M., K.Y., N.D., E.M.K. and I.I.T.; writing-original draft preparation, M.M.; writing—review and editing, M.M. and I.I.T.; visualization, M.M., K.Y. and N.D.; supervision, M.M.; project administration, M.M. and I.I.T.; funding acquisition, M.M. and I.I.T. All authors have read and agreed to the published version of the manuscript.

Funding: This work was supported by JSPS-RFBR Bilateral Joint Research Projects, JSPS project number JSPSBP120204807 and RFBR project number 20-53-50011, Funds for the Development of Human Resources in Science and Technology "2019 Initiative for Realizing Diversity in the Research Environment (Leading Type)", The Ministry of Education, Culture, Sports, Science, and Technology (MEXT), and JSPS KAKENHI (grant numbers 16H06064 and 20H02043).

Institutional Review Board Statement: Not applicable.

Informed Consent Statement: Not applicable.

Data Availability Statement: Not applicable.

Acknowledgments: The SEM/EDS observation was performed at the Nagaoka University of Technology Analysis and Instrumentation Center. We thank Nagaoka University of Technology Analysis and Instrumentation Center for use of facilities and equipment.

Conflicts of Interest: The authors declare no conflict of interest.

\section{References}

1. Tumkin, I.I.; Khairullina, E.M.; Panov, M.S.; Yoshidomi, K.; Mizoshiri, M. Copper and nickel microsensors produced by selective laser reductive sintering for non-enzymatic glucose detection. Materials 2021, 14, 2493. [CrossRef] [PubMed]

2. Zenou, M.; Ermak, O.; Saar, A.; Kotler, Z. Laser sintering of copper nanoparticles. J. Phys. D Appl. Phys. 2014, 47, 025501. [CrossRef]

3. Soltani, A.; Khorramdel Vahed, B.; Mardoukhi, A.; Mantysalo, M. Laser sintering of copper nanoparticles on top of silicon substrates. Nanotechnology 2016, 27, 035203. [CrossRef]

4. Kang, J.S.; Kim, H.S.; Ryu, J.; Thomas Hahn, H.; Jang, S.; Joung, J.W. Inkjet printed electronics using copper nanoparticle ink. J. Mater. Sci. Mater. Electron. 2010, 21, 1213-1220. [CrossRef]

5. Kang, B.; Han, S.; Kim, J.; Ko, S.; Yang, M. One-step fabrication of copper electrode by laser-induced direct local reduction and agglomeration of copper oxide nanoparticle. J. Phys. Chem. C 2011, 115, 23664-23670. [CrossRef]

6. Lee, H.; Yang, M. Effect of solvent and PVP on electrode conductivity in laser-induced reduction process. Appl. Phys. A 2015, 119, 317-323. [CrossRef]

7. Lee, D.; Paeng, D.; Park, H.K.; Grigoropoulos, C.P. Vacuum-free, maskless patterning of Ni electrodes by laser reductive sintering of NiO nanoparticle ink and its application to transparent conductors. ACS Nano 2014, 8, 9807-9814. [CrossRef] [PubMed]

8. Paeng, D.; Lee, D.; Yeo, J.; Yoo, J.-H.; Allen, F.I.; Kim, E.; So, H.; Park, H.K.; Minor, A.M.; Grigoropoulos, C.P. Laser-induced reductive sintering of nickel oxide nanoparticles under ambient conditions. J. Phys. Chem. C 2015, 119, 6363-6372. [CrossRef]

9. Mizoshiri, M.; Arakane, S.; Sakurai, J.; Hata, S. Direct writing of Cu-based micro-temperature detectors using femtosecond laser reduction of $\mathrm{CuO}$ nanoparticles. Appl. Phys. Express 2016, 9, 036701. [CrossRef]

10. Mizoshiri, M.; Kondo, Y. Direct writing of $\mathrm{Cu}$-based fine micropatterns using femtosecond laser pulse-induced sintering of $\mathrm{Cu}_{2} \mathrm{O}$ nanospheres. Jpn. J. Appl. Phys. 2019, 58, SDDF05. [CrossRef]

11. Mizoshiri, M.; Yoshidomi, K. Cu patterning using femtosecond laser reductive sintering of $\mathrm{CuO}$ nanoparticles under inert gas injection. Materials 2021, 14, 3285. [CrossRef] 
12. Mizoshiri, M.; Hata, S. Selective fabrication of p-type and n-type thermoelectric micropatterns by the reduction of $\mathrm{CuO} / \mathrm{NiO}$ mixed nanoparticles using femtosecond laser pulses. Appl. Phys. A 2017, 124, 64. [CrossRef]

13. Mizoshiri, M.; Nishitani, K.; Hata, S. Effect of heat accumulation on femtosecond laser reductive sintering of mixed CuO/NiO nanoparticles. Micromachines 2018, 9, 264. [CrossRef]

14. Ge, X.; Gu, C.D.; Wang, X.L.; Tu, J.P. Correlation between microstructure and electrochemical behavior of the mesoporous $\mathrm{Co}_{3} \mathrm{O}_{4}$ sheet and its ionothermal synthesized hydrotalcite-like $\alpha-\mathrm{Co}(\mathrm{OH})_{2}$ precursor. J. Phys. Chem. C 2013, 118, 911-923. [CrossRef]

15. Yu, J.; Ni, Y.; Zhai, M. Highly selective non-enzyme glucose detection based on $\mathrm{Co}-\mathrm{CoO}-\mathrm{Co}_{3} \mathrm{O}_{4}$ nanocomposites prepared via a solution-combustion and subsequent heat-treating route. J. Alloys Compd. 2017, 723, 904-911. [CrossRef]

16. Xu, J.M.; Cheng, J.P. The advances of $\mathrm{Co}_{3} \mathrm{O}_{4}$ as gas sensing materials: A review. J. Alloys Compd. 2016, 686, 753-768. [CrossRef]

17. Smikhovskaia, A.V.; Panov, M.S.; Tumkin, I.I.; Khairullina, E.M.; Ermakov, S.S.; Balova, I.A.; Ryazantsev, M.N.; Kochemirovsky, V.A. In Situ laser-induced codeposition of copper and different metals for fabrication of microcomposite sensor-active materials. Anal. Chim. Acta 2018, 1044, 138-146. [CrossRef] [PubMed]

18. Smikhovskaia, A.V.; Andrianov, V.S.; Khairullina, E.M.; Lebedev, D.V.; Ryazantsev, M.N.; Panov, M.S.; Tumkin, I.I. In Situ laser-induced synthesis of copper-silver microcomposite for enzyme-free d-glucose and l-alanine sensing. Appl. Surf. Sci. 2019, 488, 531-536. [CrossRef]

19. Mizoshiri, M.; Ito, Y.; Arakane, S.; Sakurai, J.; Hata, S. Direct fabrication of $\mathrm{Cu} / \mathrm{Cu}_{2} \mathrm{O}$ composite micro-temperature sensor using femtosecond laser reduction patterning. Jpn. J. Appl. Phys. 2016, 55, 06GP05. [CrossRef]

20. Back, S.; Kang, B. Low-cost optical fabrication of flexible copper electrode via laser-induced reductive sintering and adhesive transfer. Opt. Lasers Eng. 2018, 101, 78-84. [CrossRef]

21. Mizoshiri, M.; Mikami, M.; Ozaki, K. Thermal-photovoltaic hybrid solar generator using thin-film thermoelectric modules. Jpn. J. Appl. Phys. 2012, 51, 06FL07. [CrossRef]

22. Zacharatos, F.; Karvounis, P.; Theodorakos, I.; Hatziapostolou, A.; Zergioti, I. Single step laser transfer and laser curing of ag nanowires: A digital process for the fabrication of flexible and transparent microelectrodes. Materials 2018, 11, 1036. [CrossRef] [PubMed]

23. Available online: https://www.films.toray/en/technical/lumirror/lum_002.html (accessed on 10 October 2021).

24. Pal, J.; Chauhan, P. Study of physical properties of cobalt oxide $\left(\mathrm{Co}_{3} \mathrm{O}_{4}\right)$ nanocrystals. Mater. Charact. 2010, 61, 575-579. [CrossRef]

25. Makhlouf, S.A.; Bakr, Z.H.; Aly, K.I.; Moustafa, M.S. Structural, electrical and optical properties of $\mathrm{Co}_{3} \mathrm{O}_{4}$ nanoparticles. Superlattices Microstruct. 2013, 64, 107-117. [CrossRef]

26. Chen, M.; Hallstedt, B.; Ludwig, J.G. Thermodynamic assessment of the Co-O system. J. Phase Equilibria 2003, $24,212-227$. [CrossRef]

27. Ha, N.P.; Ohishi, T.; Mizoshiri, M. Direct writing of $\mathrm{Cu}$ patterns on polydimethylsiloxane substrates using femtosecond laser pulse-induced reduction of glyoxylic acid copper complex. Micromachines 2021, 12, 493. [CrossRef] [PubMed]

28. Mizoshiri, M.; Aoyama, K.; Uetsuki, A.; Ohishi, T. Direct writing of copper micropatterns using near-infrared femtosecond laser-pulse-induced reduction of glyoxylic acid copper complex. Micromachines 2019, 10, 401. [CrossRef] [PubMed]

29. Turnbull, L.; Liggat, J.J.; MacDonald, W.A. Thermal degradation chemistry of poly(ethylene naphthalate)—A study by thermal volatilisation analysis. Polym. Degrad. Stab. 2013, 98, 2244-2258. [CrossRef]

30. Khairullina, E.M.; Panov, M.S.; Andriianov, V.S.; Ratautas, K.; Tumkin, I.I.; Račiukaitis, G. High rate fabrication of copper and copper-gold electrodes by laser-induced selective electroless plating for enzyme-free glucose sensing. RSC Adv. 2021, 11, 19521-19530. [CrossRef] 